\title{
Cadaver-based abscess model for medical training
}

This article was published in the following Dove Press journal:

Advances in Medical Education and Practice

18 January 2017

Number of times this article has been viewed

\author{
Michael Stanley Ellis' \\ Joseph T Nelson ${ }^{2}$ \\ Jeffrey Zane Kartchner' \\ Karl Andrew Yousef ${ }^{\prime}$ \\ William J Adamas-Rappaport ${ }^{3}$ \\ Richard Amini ${ }^{4}$ \\ 'College of Medicine, The University \\ of Arizona, Tucson, AZ, USA; \\ ${ }^{2}$ Department of Orthopedic Surgery, \\ The University of Michigan, Ann Arbor, \\ MI, USA; ${ }^{3}$ Department of Surgery, \\ ${ }^{4}$ Department of Emergency Medicine, \\ The University of Arizona, Tucson, \\ AZ, USA
}

\begin{abstract}
Ultrasound imaging is a rapid and noninvasive tool ideal for the imaging of soft tissue infections and is associated with a change of clinician management plans in $50 \%$ of cases. We developed a realistic skin abscess diagnostic and therapeutic training model using fresh frozen cadavers and common, affordable materials. Details for construction of the model and suggested variations are presented. This cadaver-based abscess model produces high-quality sonographic images with internal echogenicity similar to a true clinical abscess, and is ideal for teaching sonographic diagnostic skills in addition to the technical skills of incision and drainage or needle aspiration. Keywords: undergraduate medical education, abscess model, ultrasound, ultrasound education, ultrasound-guided needle aspiration
\end{abstract}

\section{Introduction}

Soft tissue infections are common presenting entities that range from cellulitis to abscess. ${ }^{1,2}$ Ultrasound is increasingly used to guide the management of soft tissue infections. In fact, when ultrasound is used in patients with cellulitis, clinicians change their management plans $50 \%$ of the time. ${ }^{3}$ Incision and drainage and needle aspiration have been widely accepted as the appropriate treatment of abscesses.$^{4}$ Criticisms of the synthetic training models are that they have less realistic tactile features and subpar sonographic imaging when compared to cadaver-based models. Although various educational models for training exist in the literature, they have not attempted to simulate the realism of a true abscess under sonographic imaging using a cadaver model..$^{5-7}$ With the increased utilization of diagnostic ultrasound in medical practice, abscess training models must incorporate the use of ultrasound in these medical training models. ${ }^{8}$ Furthermore, educational procedural opportunities must be increased to achieve various competencies. The aim of this study is to describe a cadaver-based abscess model designed to aid medical student learning of physical exam and sonographic features associated with soft tissue abscesses, while providing increased exposure to and practice of the incision and drainage or needle aspiration procedures.

\section{Methods}

The use of cadavers as a platform for ultrasound training has been shown to increase student confidence in performing future ultrasound-guided skills at our institution. ${ }^{9}{ }^{910} \mathrm{In}$ addition to a fresh cadaver, the following materials are needed to prepare this training model: a latex balloon, ultrasound gel, normal saline, a number 11 or 15 blade, and an 18-guage needle with $10 \mathrm{cc}$ syringe.
Correspondence: Richard Amini University of Arizona, PO Box 245057

Tucson, AZ 85724-5057, USA

Tel +l 5206269604

Fax +I 5206262480

Email richardamini@gmail.com 
The process begins with the creation of the model abscess. Realistic abscess content texture and echogenicity is simulated using a 1:1 mixture of ultrasound gel:saline. This mixture is inserted via a syringe into a small, round balloon, which is then tied off with suture. (Suture tails may be left to later assist in removal of the balloon from the cadaver following the simulation). The fluid-filled balloon serves numerous functions: it prevents the extravasation of contents; it provides tactile rebound; and provides the sensation of cutting through the wall of an abscess. The balloon method also allows for variation of size and differing degrees of tautness to be simulated depending on the size of the balloon and amount of fluid infused. The overall result is a realistic abscess model with an echogenicity similar to a real abscess cavity and is ideal for ultrasound diagnosis (Figure 1) or needle guidance (Figure 2).

Following fluid-filled balloon creation, the balloon is then inserted into the cadaver. To insert the balloon, the skin is incised $4-5 \mathrm{~cm}$ distal to the proposed site for balloon placement and a tunnel is created under the cadaveric skin
(Figure 3A). Blunt dissection using a large aortic clamp is used to form a tunnel through the subcutaneous tissues from the incision site to the desired location for the abscess (Figure 3B). Using the clamp to grasp the tied end of the balloon will help prevent rupture or damage during placement (Figure 3C). The balloon can then be passed through the subcutaneous tunnel and placed in the desired location (Figure 3D). Once the distal incision is closed, simulation and procedural training can proceed.

\section{Results}

The surface quality of the fresh cadaver was very realistic (Figures 1 and 2). The unique anatomy of each cadaver was similar to the variable anatomy found in true clinical encounters. Although lacking palpable warmth and erythema, the abscesses were fluctuant on palpation. The desired placement was well maintained even with repeated palpation and sonographic examination. The cavities were able to be placed in a variety of different anatomic locations as well as at different depths to simulate various clinical scenarios and appearances.

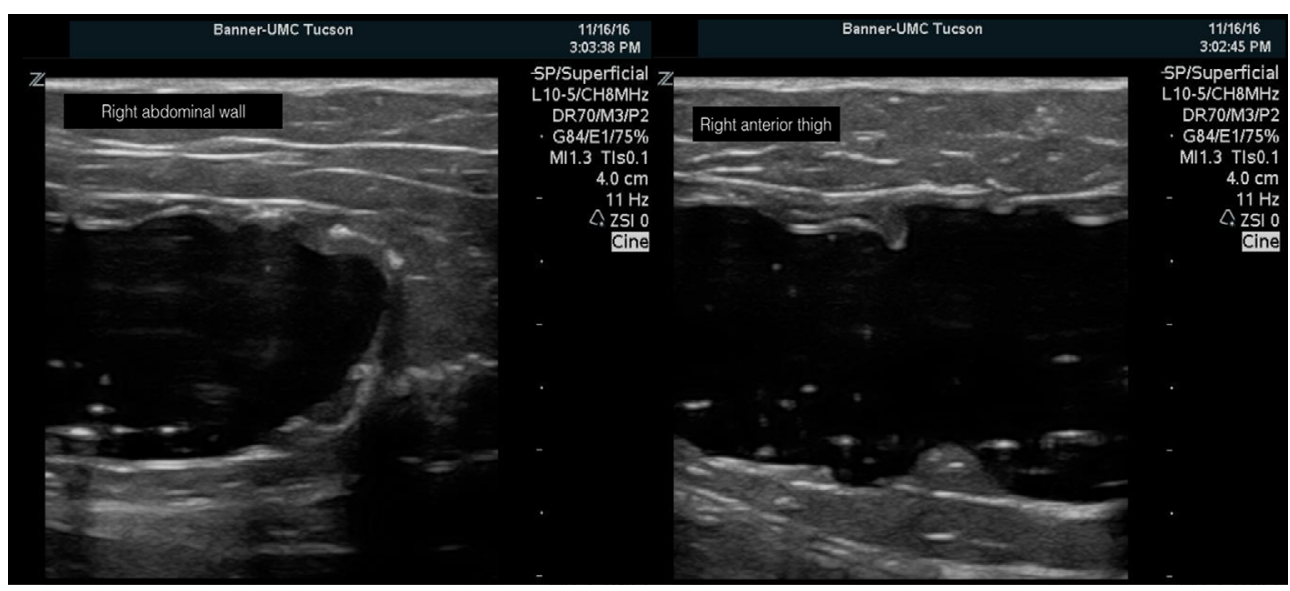

Figure I Ultrasound image showing two simulated subcutaneous abscess cavities (4 cm total depth).

Notes: Left: abscess placed in soft tissue of the abdominal wall. Right: abscess placed in soft tissue of the anterior thigh.

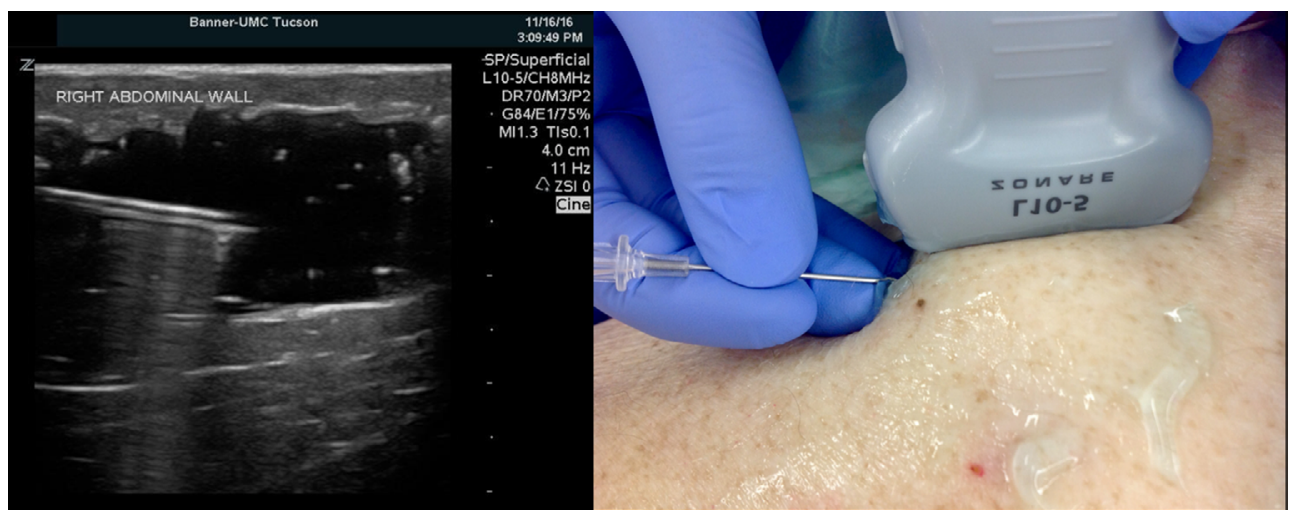

Figure 2 Ultrasound image demonstrating needle drainage technique.

Notes: Left: sonographic needle guidance. Right: anatomic image demonstrating needle guidance. 


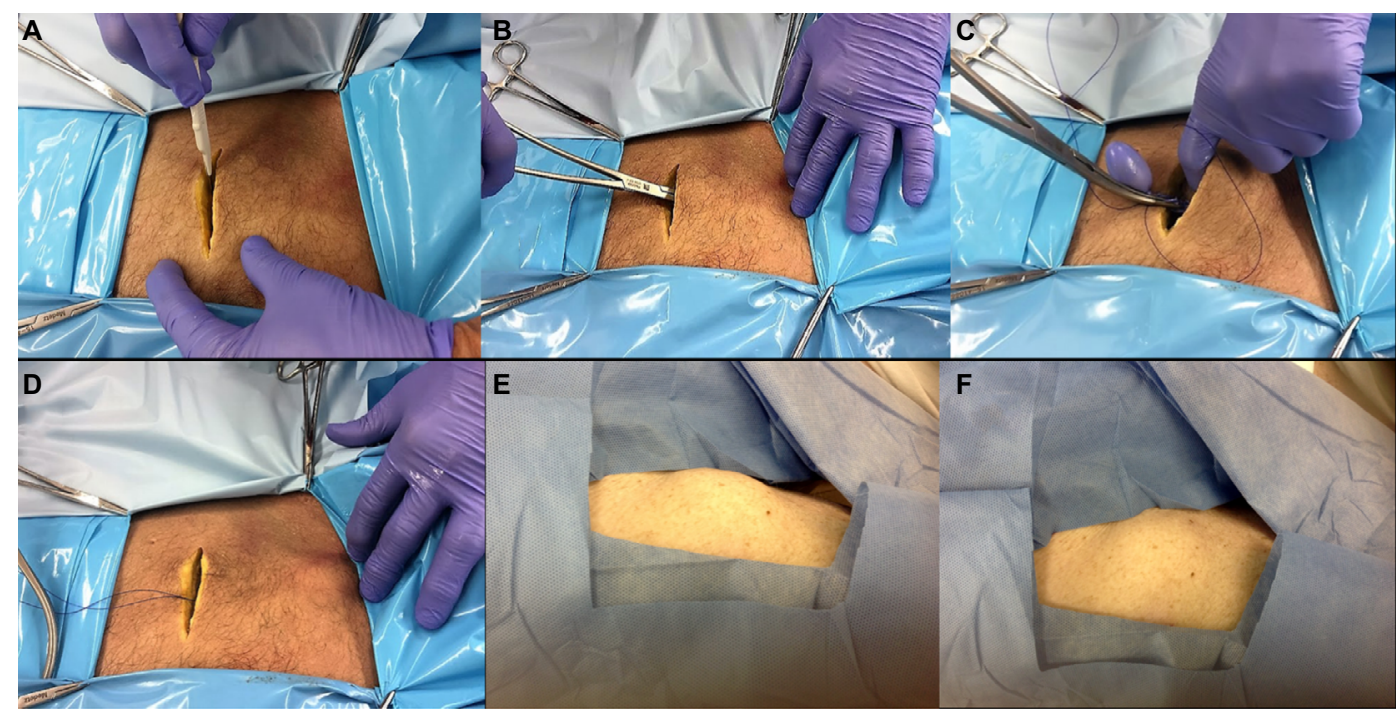

Figure 3 Cadaver-based abscess model.

Notes: (A) Creating the initial incision used for tunneling and placement of the balloon. (B) Tunneling through subcutaneous tissues using large clamp to reach desired location. (C) Grasping the prepared balloon by the tied end in preparation for passing it through the tunneled tissue. (D) The balloon is confirmed to be in proper position prior to closure of the skin. (E) Abscess balloon placed superficially with a larger visual bulge. (F) Abscess balloon placed deeper below skin surface making a visual diagnosis more difficult.

Ultrasound imaging produced high-quality images of the abscess. The abscesses maintained an oblong compressible cross section. The internal echogenicity was similar to that of a true abscess (Figure 1). The use of fresh frozen cadavers provided realistic resistance during incision and drainage. Postprocedure ultrasound was able to demonstrate residual abscess contents when complete drainage was not achieved.

\section{Discussion}

Multiple factors are making it increasingly difficult for medical trainees to obtain technical proficiency in various procedures during clerkship years. ${ }^{11}$ This has created a need to provide simple and effective methods for training. The model described in this paper provides a novel training experience with the potential to increase early exposure and training of novice practitioners to the common clinical procedures (incision and drainage and needle aspiration). This model can be used in combination with other dry lab educational sessions to improve clinician diagnostic and procedural skills.

The cadaver-based model discussed here uses common materials and is not time intensive to prepare. The use of a cadaver and abscess model allows for both physical exam skill training as well as diagnostic skill training as a result of the model's visual and tactile realism. An array of distinct clinical scenarios and appearances can be simply recreated by placing the abscess balloon in a variety of different anatomic locations and/or depths (Figure 3E and F). Variations in abscess size are easily achieved by using different size balloons and by varying the volume introduced. Furthermore, with careful tunneling, this method also lends itself to the placement of multiple abscesses through a single preparation incision. This allows greater utilization of undisturbed locations for abscess simulation.

The ultrasound image quality obtained with this model demonstrates the natural echogenicity (of facial planes) present in clinical soft tissue abscesses and is superior to synthetic simulators. The cadaver provides realistic soft tissue and anatomic context. This model is ideal, because it is important for students to learn both procedural and diagnostic skills. It has been well-established that the use of ultrasound for the assessment of soft tissue infections has been found to influence patient management in Emergency Department settings. ${ }^{3}$ Our purpose was to create an abscess model that was cadaver based and thus generate improved physical exam findings (palpation, inspection) as well as improve sonographic imaging (diagnosis) as compared to a synthetic model. We believe this model is an excellent alternative to current abscess simulations due to its ease of setup, low-cost materials, and the degree of realism.

\section{Limitations}

The major limitation to this model is the cost and availability of cadavers due to dependence upon the Willed Body Program and the monumental and generous gift of our donors. This cost can be defrayed through using each cadaver for multiple other training simulations. This also helps to maximize the benefit of each donation. An additional technical limitation is the inability to simulate loculations within the 
abscess. We did not evaluate the effectiveness of the model for teaching and retaining procedural methods of proper abscess identification, incision, and drainage. Finally, we did not directly compare this model to alternative abscess models currently in use.

\section{Conclusion}

Our model successfully replicates the clinical and ultrasound appearance of an abscess. It is ideal for simulating an abscess cavity for identification of abscesses as well as the technical skills of incision and drainage or needle aspiration. Further research is needed to evaluate the effectiveness of this model as a teaching tool.

\section{Acknowledgments}

The authors would like to thank Jared and Kat Alverado for their help in the cadaver lab. Their work is vital to ongoing medical education at numerous institutions. We are fortunate to have them.

This study did not require ethics approval, as the College of Medicine (University of Arizona) currently conducts education-related evaluation and research activities under a site level institutional review board "exempt" approval. This approval is exempt as "research conducted in established or commonly accepted educational settings, involving normal educational practices, such as research on regular and special education instructional strategies".

\section{Disclosure}

The authors report no conflicts of interest in this work.

\section{References}

1. Mistry RD. Skin and soft tissue infections. Pediatr Clin North Am. 2013;60(5):1063-1082.

2. Bergeson PS, Singer SA, Kaplan AM. Intramuscular injections in children. Pediatrics. 1982;70:944.

3. Tayal VS, Hasan N, Norton HJ, Tomaszewski CA. The effect of soft tissue ultrasound on the management of cellulitis in the emergency department. Acad Emerg Med. 2006;13(4):384-388.

4. Butler KH. Chapter 37 Incision and Drainage. In: Custalow CB, Chanmugam AS, Chudnofsky CR, McManus J, Roberts JR, Hedges JR, editors. Roberts and Hedges 'Clinical Procedures in Emergency Medicine, 5th ed. Philadelphia, PA: Saunders; 2010:657-691.

5. Fitch MT, Manthey DE, McGinnis HD, Nicks BA, Pariyadath M. A skin abscess model for teaching incision and drainage procedures. BMC Med Educ. 2008;3(8):38.

6. Heiner JD. A new simulation model for skin abscess identification and management. Simul Healthc. 2010;5(4):238-241.

7. Cole FL, Ramirez E, Mickanin J. Skill station models for teaching incision and drainage of abscesses, felons, and paronychia to emergency nurse practitioners. Emerg Nurs. 1998;24:455-456.

8. Amini R, Kartchner JZ, Stolz L, Biffar D, Hamilton AJ, Adhikari S. A novel and inexpensive ballistics gel phantom for ultrasound training. World J Emerg Med. 2015;6(3):225.

9. Hoyer R, Means R, Robertson J, et al. Ultrasound-guided procedures in medical education: a fresh look at cadavers. Intern Emerg Med. 2015; 11(3):431-436.

10. Miller $\mathrm{R}, \mathrm{Ho} \mathrm{H}, \mathrm{Ng} \mathrm{V}$, et al. Introducing a fresh cadaver model for ultrasound-guided central venous access training in undergraduate medical education. West J Emerg Med. 2016;17(3):362-366.

11. Kaplan SJ, Carroll JT, Nematollahi S, Chuu, A, Adamas-Rappaport W, Ong E. Utilization of a non-preserved cadaver to address deficiencies in technical skills during the third year of medical school: a cadaver model for teaching technical skills. World J Surg. 2013;37(5):953-955.
Advances in Medical Education and Practice

\section{Publish your work in this journal}

Advances in Medical Education and Practice is an international, peerreviewed, open access journal that aims to present and publish research on Medical Education covering medical, dental, nursing and allied health care professional education. The journal covers undergraduate education, postgraduate training and continuing medical education

\section{Dovepress}

including emerging trends and innovative models linking education, research, and health care services. The manuscript management system is completely online and includes a very quick and fair peer-review system. Visit http://www.dovepress.com/testimonials.php to read real quotes from published authors. 